\title{
Late recurrence of hepatocellular carcinoma after liver transplantation
}

\author{
Julia A. Zhang', Sandi A. Kwee'2, Linda L. Wong ${ }^{1}$ \\ ${ }^{1}$ Department of Surgery, University of Hawaii School of Medicine, Honolulu, HI 96813, USA. \\ ${ }^{2}$ The Queens Medical Center, Honolulu, HI 96813, USA.
}

Correspondence to: Prof. Linda L. Wong, Department of Surgery, University of Hawaii School of Medicine, 550 S. Beretania Street, Suite 403, Honolulu, HI 96813, USA. E-mail: Hepatoma@aol.com

How to cite this article: Zhang JA, Kwee SA, Wong LL. Late recurrence of hepatocellular carcinoma after liver transplantation Hepatoma Res 2017;3:58-66.

\section{Article history: \\ Received: 29-01-2017 \\ Accepted: 24-03-2017 \\ Published: 10-04-2017 \\ Key words: \\ Hepatocellular carcinoma, \\ liver transplantation, recurrence}

\section{INTRODUCTION}

Hepatocellular carcinoma ( $\mathrm{HCC}$ ) is the most common primary liver cancer with 782,000 new cases and 745,000 deaths annually worldwide. ${ }^{[1]}$ The best treatments for HCC include liver resection and liver transplantation (LT). However, most patients present at advanced stage and are not candidates for these potentially curative therapies. LT, although limited by the shortage of donor livers, has superior diseasefree survival, with improved 5 -year survival of $70 \%$

\begin{abstract}
Aim: Hepatocellular carcinoma (HCC) is the third leading cause of cancer deaths worldwide and liver transplant (LT) prolongs survival. However, $15-20 \%$ will experience recurrent HCC, most occurring within 2 years of LT. HCC patients with late recurrences $(>5$ years after LT) may have distinctive clinical/biological characteristics. Methods: A retrospective review was conducted of 88 patients who underwent LT for HCC during 1993-2015, analyzing demographics, clinical factors, explant pathology, and outcome. Results: Median follow-up was 6.4 years. HCC recurred in $15(17.0 \%)$ patients with mean time to recurrence of $3.96 \pm$ 3.99 years. Five patients reoccurred $>5$ years post-LT. All late recurrences involved males in their 50 s, recurring at 8.5 years on average. Recurrences occurred in chest wall (2), liver (2), lung (2), bone (1) and pelvis (1), with multifocal involvement in 2 patients. Four patients died within 18 months of late recurrence. The fifth patient is alive after ablation of liver recurrence and treatment with sorafenib and everolimus. Conclusion: One-third of post-LT patients with recurrent HCC experienced late recurrence. Although the sample size makes it difficult to identify significant risk factors, this study highlights the importance of long-term follow-up and need for biomarkers to identify patients at risk for late recurrences.
\end{abstract}

compared to $10 \%$ in untreated $\mathrm{HCC} .{ }^{[2]}$ Despite receiving optimal therapy with transplantation, up to $20 \%$ of patients may experience recurrent HCC. Most of these recurrences occur within 2 years following transplantation. Although there are no clear guidelines on how to treat these recurrences, surgical resection is the preferred treatment option. Other locoregional therapies such as radiofrequency ablation (RFA) and transarterial chemoembolization (TACE) may be options, and sorafenib can be considered for more diffuse, unresectable disease..$^{[3,4]}$ 
Unfortunately there is little evidence of the survival benefits following treatment for recurrent HCC following transplant. In addition, few studies have examined risk factors in recurrent HCC after transplant or prognostic factors for survival after recurrence. Moreover, while tumor recurrence tends to happen within the first two years following transplantation, late recurrence can occur and the pathobiology underlying these cases is not well understood. This study aims to identify and characterize cases of late recurrent HCC after transplantation in Hawaii, a state with a high burden of liver disease and cancer due to a large population of Asians and Pacific Islanders with viral hepatitis. $^{[5-7]}$

\section{METHODS}

This is a retrospective analysis of 88 patients who underwent LT for HCC from 1993 to 2015. All patients were referred to a group of physicians associated with the medical center with the only LT program in the state of Hawaii. It is also the primary referral center for hepatobiliary surgery for American Samoa, Guam, Saipan, and the Marshall Islands. This clinic and the transplant center were initially affiliated with Hawaii Medical Center-East (formerly St. Francis Medical Center) and after 2012, the Queens Medical Center. This center sees about $60-70 \%$ of the HCC cases in Hawaii. This study was approved by the University of Hawaii Institutional Review Board.

HCC was diagnosed histologically by percutaneous biopsy or at surgery. The diagnosis of HCC was made with only imaging if a contrast-enhanced study [dynamic computed tomography (CT) or magnetic resonance imaging (MRI)] showed typical arterial enhancement with "washout" in the venous phase as described by the American Association for the Study of Liver Disease guidelines. ${ }^{[8]}$ All patients received transplant livers from deceased donors. For immunosuppression after LT, patients all received basiliximab for induction, steroids, tacrolimus, and mycophenolate mofetil. All patients were weaned off of steroids after 6 months and maintenance immunosuppression was continued with tacrolimus or tacrolimus/mycophenolate.

Information on demographics, medical history, laboratory results, tumor characteristics, treatment, and survival was collected via clinical interviews. Demographic data included age, gender, birthplace, and the patient's self-reported ethnicity. Data collected on medical history included diabetes mellitus, hyperlipidemia, smoking, and risk factors for HCC including viral hepatitis, alcohol abuse (defined as greater than 2 alcoholic beverages daily for at least 10 years), and other chronic liver diseases. Information was based on available medical records and interviews by a single physician.

Laboratory data collected included serum bilirubin, albumin, prothrombin time, creatinine, alanine aminotransferase, aspartate aminotransferase, platelet count and alpha-fetoprotein (AFP). Laboratory data that was used for the study had been obtained within 2 weeks of initial visit or drawn at the time of the visit. Serum bilirubin, prothrombin time with international normalized ratio (INR) and creatinine were used to calculate the Model for End-stage Liver Disease (MELD) score. Dynamic imaging with CT or MRI was performed to determine if Milan criteria were met (single tumor $\leq 5 \mathrm{~cm}$ or up to 3 tumors $\leq 3 \mathrm{~cm}$ each, no vascular invasion, no extrahepatic spread). Patients who met Milan criteria initially or who could be downstaged with locoregional therapy to meet Milan criteria were considered for liver transplantation.

We also noted the type of locoregional therapy that was performed before LT including RFA and TACE. Pathology reports were also examined to determine the size and number of HCC lesions present, the amount of tumor necrosis, the location of tumors, and presence of vascular invasion.

Data analysis was performed using Microsoft Excel and Statistical Package for the Social Sciences software to identify potential predictors for recurrent HCC. Fisher's and chi-square analysis was performed and $P$ values $<0.05$ were considered significant.

Five patients were identified as having a "late" recurrence, defined as the diagnosis of HCC occuring more than 5 years after the date of LT. Late recurrence cases were examined in detail for post-LT course, use of immunosuppression, site of recurrence, treatment for recurrence, and response to treatment.

\section{RESULTS}

Of 1,200 patients in our database of patients treated for HCC, 88 underwent LT for HCC and had the following characteristics were shown in Table 1: mean age 56.6 years, $83 \%$ male, $54.5 \%$ Asian, $10.2 \%$ Pacific Islanders, 58\% hepatitis B positive, $61.4 \%$ hepatitis C positive, $30.7 \%$ with diabetes, and $46.6 \%$ with normal AFP $(<20)$. Locoregional therapy was performed in 67 patients $(76.1 \%)$ with 26 receiving only RFA and 17 received only TACE. Cases with single tumors less than $2.5 \mathrm{~cm}$ in easily accessible locations were chosen for RFA. Cases with larger 
Table 1: Baseline characteristics of patients in study $(n=88)$

\begin{tabular}{lc}
\hline Characteristics & Data, $\boldsymbol{n}(\%)$ \\
\hline Age, years, mean \pm SD (range) & $56.6 \pm 6.1(41-72)$ \\
Males & $73(83.0)$ \\
Ethnicity & \\
Asian & $48(54.5)$ \\
Pacific Islanders & $9(10.2)$ \\
Black & $1(1.1)$ \\
Hispanic & $2(2.3)$ \\
White & $26(29.5)$ \\
Mixed & $2(2.3)$ \\
Hepatitis B & $51(58.0)$ \\
Hepatitis C & $54(61.4)$ \\
Diabetes & $27(30.7)$ \\
AFP, mean \pm SD & $669.7 \pm 3,739.6$ \\
Patients receiving locoregional therapy & $67(76.1)$ \\
RFA only & $26(29.5)$ \\
TACE only & $17(19.3)$ \\
\hline
\end{tabular}

AFP: alpha-fetoprotein; RFA: radiofrequency ablation; TACE: transarterial chemoembolization

tumors and multiple tumors were treated with TACE. Median duration of follow-up was 6.4 years (mean 6.8 years, range 8 days -17.2 years).

Univariate analysis suggested the presence of microvascular invasion as seen on pathology and size of the largest tumor in the explant to be predictors of recurrence of HCC after transplant. Other factors including age, gender, race, presence of hepatitis $B$ or $\mathrm{C}$, diabetes, AFP level, locoregional treatment, and presence of 4 or more tumors in the explanted liver did not predict recurrence [Table 2].

Recurrent HCC occurred in 15 cases $(17.0 \%)$ with mean time to recurrence of $3.96 \pm 3.99$ years. Seven patients recurred within 2 years and 5 recurred $>5$ years post-LT. All late recurrences involved males in their $50 \mathrm{~s}$, recurring at a mean 8.5 years (range 5.213.4 years). Explanted livers showed 1 with vascular invasion, 2 with $>4$ tumors and 2 with single tumors. Recurrences occurred in chest wall (2), liver (2), lung (2), bone (1) and pelvis (1), with 2 patients having recurrent tumors in multiple sites. Four patients died within 18 months of late recurrence. The fifth patient is alive for 3 years after ablation of liver recurrence and treatment with sorafenib and everolimus. Table 3 lists details of the late recurrence cases and Table 4 shows a comparison of early and late recurrence cases. Clinical summaries of the 5 cases of late recurrence are reported below.

\section{Case 1}

The first case is a 53-year-old Chinese male with hepatitis $B$ cirrhosis and 2 liver masses $(3.4$ and $2.1 \mathrm{~cm}$ ). AFP was $2,397 \mathrm{ng} / \mathrm{mL}$ and liver biopsy showed a well-differentiated HCC. He underwent RFA followed by TACE and LT 1 month later. The explanted liver showed multifocal HCC without microvascular invasion including $4.5 \mathrm{~cm}, 3.0 \mathrm{~cm}$ and $1.8 \mathrm{~cm}$ masses with $95-100 \%$ necrosis, and a $1.8 \mathrm{~cm}$ caudate lobe mass with $10 \%$ necrosis.

Table 2: Characteristics of patients with recurrence vs. without recurrence, $n(\%)$

\begin{tabular}{|c|c|c|c|}
\hline Characteristics & Recurrence $(n=15)$ & No recurrence $(n=73)$ & $P$ value \\
\hline Age, years, mean $\pm S D$ & $58.1 \pm 3.1$ & $56.3 \pm 6.5$ & 0.30 \\
\hline Males & $11(73.3)$ & $62(85.0)$ & 0.28 \\
\hline Asians & $10(66.7)$ & $38(52.1)$ & 0.40 \\
\hline Hepatitis B & $8(53.3)$ & $21(28.8)$ & 0.08 \\
\hline Hepatitis C & $7(46.7)$ & $47(64.4)$ & 0.25 \\
\hline Diabetes & $6(40.0)$ & $21(28.8)$ & 0.54 \\
\hline Imaging: largest tumor size, $\mathrm{cm}$, mean $\pm \mathrm{SD}$ & $3.1 \pm 1.2$ & $2.9 \pm 1.3$ & 0.60 \\
\hline Explant: largest tumor size, $\mathrm{cm}$, mean $\pm \mathrm{SD}$ & $3.9 \pm 2.0$ & $2.4 \pm 1.2$ & 0.001 \\
\hline Explant: largest tumor $>3 \mathrm{~cm}$ & $6 / 11^{\star}(54.5)$ & $19 / 66^{\star}(28.8)$ & 0.16 \\
\hline Imaging: no. of tumors, mean \pm SD & $1.2 \pm 0.6$ & $1.3 \pm 0.6$ & 0.60 \\
\hline Explant: no. of tumors, mean \pm SD & $3.1 \pm 3.6$ & $2.0 \pm 1.9$ & 0.13 \\
\hline Explant: $>4$ tumors & $5 / 13^{*}(38.5)$ & $10 / 67^{*}(15.0)$ & 0.06 \\
\hline Well differentiated tumor & $2 / 13^{*}(15.4)$ & $15 / 58^{*}(25.9)$ & 0.72 \\
\hline Met milan criteria & $13(86.7)$ & $57 / 72^{*}(79.2)$ & 0.73 \\
\hline AFP at diagnosis, $\mathrm{ng} / \mathrm{mL}$, mean $\pm \mathrm{SD}$ & $829.9 \pm 2,401.1$ & $637.7 \pm 3,966.1$ & 0.86 \\
\hline AFP $>500 \mathrm{ng} / \mathrm{mL}$ & $2 / 14$ & $7 / 70$ & 0.64 \\
\hline AFP $>1,000 \mathrm{ng} / \mathrm{mL}$ & $2 / 14$ & $5 / 70$ & 0.33 \\
\hline Lab MELD score, mean \pm SD & $11 \pm 3.9$ & $12 \pm 3.8$ & 0.74 \\
\hline Received locoregional therapy & $12(80.0)$ & $55(75.3)$ & 1.00 \\
\hline Waiting time (from diagnosis to $L T$ ), days, mean \pm SD & $193.4 \pm 163.9$ & $315.8 \pm 367.3$ & 0.21 \\
\hline Explanted liver met Milan criteria & $7 / 13^{*}(53.8)$ & $47 / 67^{\star}(70.1)$ & 0.33 \\
\hline Explanted liver with microvascular invasion & $5 / 13^{*}(38.5)$ & $1 / 59^{*}(1.7)$ & 0.001 \\
\hline
\end{tabular}

*Data not available for all patients. No. of cases for which data was available is indicated. AFP: alpha-fetoprotein; MELD: Model for Endstage Liver Disease; LT: liver transplantation 
Table 3: Late recurrence cases (more than 5 years after LT)

\begin{tabular}{|c|c|c|c|c|c|c|c|c|c|c|}
\hline $\begin{array}{l}\text { Age/ } \\
\text { gender }\end{array}$ & $\begin{array}{l}\text { Time to } \\
\text { recurrence } \\
\text { (years) }\end{array}$ & $\begin{array}{l}\text { Site of } \\
\text { recurrence }\end{array}$ & $\begin{array}{c}\text { Preop } \\
\text { biopsy }\end{array}$ & $\begin{array}{l}\text { AFP pre- } \\
\text { LT (ng/mL) }\end{array}$ & ESLD & $\begin{array}{l}\text { Size of largest } \\
\text { tumor on } \\
\text { imaging (cm) }\end{array}$ & $\begin{array}{l}\text { Explant } \\
\text { vascular } \\
\text { invasion }\end{array}$ & $\begin{array}{l}\text { Explant } \\
\text { with 4+ } \\
\text { tumors }\end{array}$ & $\begin{array}{l}\text { Treatment of } \\
\text { recurrence }\end{array}$ & $\begin{array}{l}\text { Status after } \\
\text { recurrence }\end{array}$ \\
\hline $53 / \mathrm{M}$ & 11.3 & $\begin{array}{l}\text { Chest wall, } \\
\text { liver, lung }\end{array}$ & Yes & 2,387 & HBV & 3.4 & No & Yes & $\begin{array}{l}\text { Resect chest } \\
\text { wall mass, left } \\
\text { liver, everolimus }\end{array}$ & $\begin{array}{l}\text { Deceased, } \\
8 \text { months }\end{array}$ \\
\hline $57 / M$ & 5.9 & Chest wall & Yes & 34 & $\mathrm{HCV}$ & 2.0 & No & No & $\begin{array}{l}\text { Resect chest } \\
\text { wall, radiation }\end{array}$ & $\begin{array}{l}\text { Deceased, } \\
12 \text { months }\end{array}$ \\
\hline $59 / \mathrm{M}$ & 5.2 & $\begin{array}{c}\text { Pelvic mass, } \\
\text { bone }\end{array}$ & Yes & 7 & $\mathrm{NASH}$ & 4.0 & Yes & No & $\begin{array}{l}\text { Resect pelvic } \\
\text { mass, sorafenib }\end{array}$ & $\begin{array}{l}\text { Deceased, } \\
18 \text { months }\end{array}$ \\
\hline $58 / \mathrm{M}$ & 6.6 & Liver & Yes & 46 & $\mathrm{HCV}$ & 2.3 & No & No & $\begin{array}{l}\text { RFA, everolimus, } \\
\text { sorafenib }\end{array}$ & $\begin{array}{l}\text { Living, } \\
44 \text { months }\end{array}$ \\
\hline $59 / \mathrm{M}$ & 13.4 & Lung & No & 10.2 & HBV & 2.2 & No & Yes & None & $\begin{array}{l}\text { Deceased, } \\
2 \text { months }\end{array}$ \\
\hline
\end{tabular}

AFP: alpha-fetoprotein; LT: liver transplantation; ESLD: end-stage liver disease; HBV: hepatitis B virus; HCV: hepatitis C virus; NASH: nonalcoholic steatohepatitis; RFA: radiofrequency ablation

Table 4: Characteristics of patients with early recurrence vs. late recurrence on initial presentation, $n(\%)$

\begin{tabular}{|c|c|c|c|}
\hline Characteristics & Early recurrence $(n=10)$ & Late recurrence $(n=5)$ & $P$ value \\
\hline Age, years, mean $\pm S D$ & $58.7 \pm 3.4$ & $57 \pm 2.5$ & 0.34 \\
\hline Males & $6(60.0)$ & $5(100.0)$ & 0.23 \\
\hline Asians & $7(70.0)$ & $3(60.0)$ & 1.00 \\
\hline Hepatitis B & $6(60.0)$ & $2(40.0)$ & 0.61 \\
\hline Hepatitis C & $5(50.0)$ & $2(40.0)$ & 1.00 \\
\hline Diabetes & $4(40.0)$ & $2(40.0)$ & 1.00 \\
\hline Imaging: largest tumor size, $\mathrm{cm}$, mean $\pm \mathrm{SD}$ & $3.3 \pm 1.3$ & $2.8 \pm 0.9$ & 0.48 \\
\hline Explant: largest tumor size, $\mathrm{cm}$, mean $\pm \mathrm{SD}$ & $4.7 \pm 2.0$ & $2.3 \pm 1.0$ & 0.05 \\
\hline Explant: largest tumor $>3 \mathrm{~cm}$ & $5 / 8^{*}(62.5)$ & $1 / 4^{*}(25.0)$ & 0.55 \\
\hline Imaging: no. of tumors, mean \pm SD & $1.2 \pm 0.6$ & $1.2 \pm 0.5$ & 1.00 \\
\hline Explant: no. of tumors, mean \pm SD & $3.3 \pm 4.3$ & $2.8 \pm 2.9$ & 0.82 \\
\hline Explant: $>4$ tumors & $3 / 8^{*}(37.5)$ & $2(40.0)$ & 1.00 \\
\hline Well differentiated tumor & $0 / 8^{*}(0)$ & $2(40.0)$ & 0.13 \\
\hline Met milan criteria & $9(90.0)$ & $4(80.0)$ & 1.00 \\
\hline AFP at diagnosis, $\mathrm{ng} / \mathrm{mL}$, mean $\pm \mathrm{SD}$ & $1,014.9 \pm 2,950.0$ & $496.8 \pm 1,056.8$ & 0.72 \\
\hline AFP $>500 \mathrm{ng} / \mathrm{mL}$ & $1 / 9^{*}$ & 1 & 1.00 \\
\hline AFP $>1,000 \mathrm{ng} / \mathrm{mL}$ & $1 / 9^{*}$ & 1 & 1.00 \\
\hline Lab MELD score, mean \pm SD & $12 \pm 4.2$ & $11 \pm 3.5$ & 0.71 \\
\hline Received locoregional therapy & $9(90.0)$ & $3(60.0)$ & 0.24 \\
\hline Waiting time (from diagnosis to $L T$ ), days, mean $\pm S D$ & $222.6 \pm 185.2$ & $135.0 \pm 102.0$ & 0.35 \\
\hline Explanted liver met Milan criteria & $3 / 8^{*}(37.5)$ & $4(80.0)$ & 0.27 \\
\hline Explanted liver with microvascular invasion & $4 / 8^{*}(50.0)$ & $1(20.0)$ & 0.56 \\
\hline
\end{tabular}

*Data not available for all patients. No. of cases for which data was available is indicated. AFP: alpha-fetoprotein; MELD: Model for Endstage Liver Disease; LT: liver transplantation

Immunosuppression consisted of steroids, mycophenolate, and tacrolimus with eventual wean to tacrolimus monotherapy. Hepatitis B was controlled with monthly hepatitis $B$ immune globulin injections and lamivudine, but he was eventually switched to adefovir and then tenofovir. Seven years post-LT, he was found to have a hepatitis B surface Ag escape mutant.

Eleven years post-LT, the patient noted a prominent xiphoid process. CT scan showed an $8.9 \mathrm{~cm}$ mass involving the left lobe of the liver, xiphoid and anterior chest wall. AFP was $60,000 \mathrm{ng} / \mathrm{mL}$ and bone scan was negative. He underwent en-bloc resection of recurrent $\mathrm{HCC}$ with partial resection of the diaphragm, pericardium, pleural and sternum, and left lateral segment of liver. After surgery, he was given sorafenib and immunosuppression was changed to very low dose tacrolimus and everolimus $0.5 \mathrm{mcg}$ twice daily. His AFP reached a nadir of $1,097 \mathrm{ng} / \mathrm{mL}$, but then increased to $60,000 \mathrm{ng} / \mathrm{mL}$. He eventually developed lung metastases and died 8 months after the surgery.

\section{Case 2}

This patient was a 57 -year-old Caucasian male who presented with decompensated hepatitis $\mathrm{C}$ cirrhosis and a $2.3 \mathrm{~cm}$ well-differentiated $\mathrm{HCC}$. He underwent RFA via an intercostal approach at the right upper abdomen/chest wall. Seven months after the biopsy, 
the patient underwent LT. Explanted liver demonstrated 2 well differentiated $\mathrm{HCC}$ in the right lobe $(1.5 \mathrm{~cm}$ and $1.0 \mathrm{~cm}$ ) with $60 \%$ necrosis and 3 non-necrotic satellite nodules measuring 0.2 to $0.3 \mathrm{~cm}$. No microvascular invasion was noted.

Four years after $\mathrm{LT}$, the patient was found to have $1.1 \mathrm{~cm}$ solid nodule in the right chest wall at the 8th rib. Needle biopsy showed necrosis and fibroinflammatory tissue reaction with a focus of metastatic HCC. Complete wide excision of this mass showed no additional HCC. Long-term immunosuppression consisted of low dose tacrolimus.

Six years post-LT, he developed another $2.4 \mathrm{~cm}$ soft tissue mass in the right lateral chest wall. This was thought to be a needle tract seeding of tumor related to a previous biopsy and RFA. Wide surgical resection was performed and revealed metastatic HCC with necrosis.

Seven years post-LT, he developed a persistent cough and CT scan showed a $1.8 \mathrm{~cm}$ mass in the left lower lung and AFP was $3 \mathrm{ng} / \mathrm{mL}$. He underwent a left thoracotomy and wedge excision of a $1.7 \mathrm{~cm}$ moderately differentiated squamous cell lung cancer (node negative). No additional therapy was given for his lung cancer.

He was disease free from both lung cancer and HCC up until 9 years post-LT when he began to complain of right rib pain. AFP was $140 \mathrm{ng} / \mathrm{mL}$. CT scan showed a multilobulated mass in the right chest wall involving the 8th and 9th ribs and adjacent diaphragm, which was separate from the liver. He underwent radiation and refused sorafenib. He eventually expired from this 1 year later.

\section{Case 3}

The third case is a 59-year-old Japanese male with non-alcoholic steatohepatitis with variceal bleeding episode. He was found to have a $3 \mathrm{~cm}$ liver mass and biopsy showed poorly differentiated HCC. Within 4 months of diagnosis, he received LT. His explanted liver showed a $3.8 \mathrm{~cm}$ moderately differentiated HCC with lymphovascular invasion. Immunosuppression consisted of basiliximab, steroids, mycophenolate mofetil and tacrolimus. Maintenance immunosuppression was with low dose tacrolimus.

Five years after transplant, a routine AFP was noted to be $70 \mathrm{ng} / \mathrm{mL}$. His AFP continued to increase but multiple imaging tests were negative. A few months later, repeat $C T$ scan showed a $3 \mathrm{~cm}$ mass in the pelvis between the internal and external iliac arteries.
He underwent surgical resection and pathology showed a $5.3 \mathrm{~cm} \mathrm{HCC}$.

Post-operatively, his immunosuppression was changed to very low dose tacrolimus and sirolimus. Sorafenib was also added. His AFP continued to increase and he also developed skeletal metastases. He expired 18 months after recurrence of HCC.

\section{Case 4}

The next case is a 66-year-old Puerto-Rican male with hepatitis $C$ cirrhosis and a $2.3 \mathrm{~cm}$ mass adjacent to the inferior vena cava. AFP was $46 \mathrm{ng} / \mathrm{mL}$. Liver biopsy demonstrated $\mathrm{HCC}$ and he underwent TACE followed by LT 4 months later. The explanted liver showed a $2.0 \mathrm{~cm}$ moderately differentiated HCC with $20 \%$ necrosis and no vascular invasion. Immunosuppression consisted of basiliximab, steroids, mycophenolate, and tacrolimus; he was gradually weaned to tacrolimus monotherapy.

Six years after transplant, AFP was noted to be $216 \mathrm{ng} / \mathrm{mL}$. CT scan showed a nonspecific $1.0 \mathrm{~cm}$ hypovascular lesion in the left lobe which increased to $2.2 \mathrm{~cm}$ on subsequent imaging. Immunosuppression was changed to very low dose tacrolimus and everolimus $0.5 \mathrm{mg}$ bid. Sorafenib was also added. He underwent RFA and subsequent CT scan showed no new lesions, but AFP increased to $10,385 \mathrm{ng} / \mathrm{mL}$ 1 month later. MRI scan showed a suspicious $5.4 \mathrm{~cm}$ mass in the left lobe. Stereotactic body radiation (SBRT) was planned and AFP decreased to $8,243 \mathrm{ng} / \mathrm{mL}$. When he arrived for SBRT simulation, the lesion could not be found. AFP decreased to $2.1 \mathrm{ng} / \mathrm{mL}$. CT scan now showed no liver lesion and resolution of the previously seen liver mass. All subsequent AFP tests have been normal. His hepatitis $C$ was successfully treated with sofosbuvir and simepravir. He is currently on everolimus and sorafenib and has no evidence of liver disease on imaging 44 months after diagnosis of recurrent HCC.

\section{Case 5}

The final case is a 59-year-old Korean male with end stage liver disease due to hepatitis B. During the LT evaluation, he was found to have a $2.2 \mathrm{~cm}$ hypervascular mass. AFP was $10.2 \mathrm{ng} / \mathrm{mL}$. He underwent LT without any locoregional therapy preoperatively. The explanted liver showed a multifocal HCC with at least 7 lesions. Immunosuppression consisted of tacrolimus and steroids.

Post-LT, he had no episodes of rejection, infection, or liver dysfunction. His hepatitis B was wellcontrolled with lamivudine and hepatitis B immune 
Table 5: Review of literature on the incidence of recurrence of HCC after LT

\begin{tabular}{|c|c|c|c|c|c|c|}
\hline Authors & Year & Area & No. of LT patients & Recurrence rate & Median follow-up & Mean follow-up \\
\hline Roayaie et al. ${ }^{[4]}$ & 2004 & USA (NY) & 311 & $18.3 \%$ & 51.9 months & \\
\hline Hwang et al. ${ }^{[9]}$ & 2011 & Korea & 87 & $1.3 \%$ & 75 months & \\
\hline Lee et al. ${ }^{[10]}$ & 2014 & Korea & 69 & $44.9 \%$ & 24.5 months & \\
\hline Schraiber et al..$^{[11]}$ & 2016 & Brazil & 206 & $15.5 \%$ & 43.6 months & 49.8 months \\
\hline Hanouneh et al. ${ }^{[12]}$ & 2011 & USA $(\mathrm{OH})$ & 92 & $13.0 \%$ & 19.5 months & \\
\hline Andreou et al..$^{[13]}$ & 2016 & Germany & 364 & $25.0 \%$ & 78 months & \\
\hline Kondili et al. ${ }^{[14]}$ & 2007 & UK & 104 & $11.5 \%$ & 36 months & 47 months \\
\hline Escartin et al. ${ }^{[15]}$ & 2007 & Spain & 184 & $15.2 \%$ & & \\
\hline Varona et al. ${ }^{[16]}$ & 2015 & Spain & 109 & $7.0 \%$ & 42 months & \\
\hline Lai et al. ${ }^{[19]}$ & 2013 & Italy, Brussels & 422 & $14.5 \%$ & 4.9 years & \\
\hline Agopian et al..$^{[20]}$ & 2015 & USA (CA) & 865 & $13.5 \%$ & 29.7 months & \\
\hline Parfitt et al. ${ }^{[21]}$ & 2007 & Spain & 75 & $26.7 \%$ & & 8 years \\
\hline Chok et al. ${ }^{[23]}$ & 2011 & Hong Kong & 139 & $17.3 \%$ & 55 months & \\
\hline Zou et al. ${ }^{[26]}$ & 2008 & China & 303 & $15.8 \%$ & & \\
\hline Rodriguez-Peralvarez et al. ${ }^{[27]}$ & 2013 & Spain & 219 & $17.6 \%$ & 51 months & \\
\hline Nissen et al. ${ }^{[28]}$ & 2011 & USA (CA) & 122 & $10.7 \%$ & 32.7 months & \\
\hline Pfiffer et al. ${ }^{[29]}$ & 2011 & Germany & 139 & $17.3 \%$ & 37.2 months & \\
\hline Marelli et al..$^{[30]}$ & 2008 & UK & 100 & $18.0 \%$ & 29 months & \\
\hline Sharma et al. ${ }^{[40]}$ & 2012 & USA (MI) & 94 & $18.0 \%$ & 2.2 years & \\
\hline Wai et al. ${ }^{[41]}$ & 2012 & Singapore & 77 & $38.0 \%$ & & 953 days \\
\hline lacob et al. ${ }^{[42]}$ & 2013 & Romania & 38 & $13.2 \%$ & & 22 months \\
\hline
\end{tabular}

HCC: hepatocellular carcinoma; LT: liver transplantation

globulin injections. Approximately 13.5 years after LT, he complained of persistent cough and was found to have a large pleural effusion. CT scan showed multiple small pulmonary nodules and hilar/ mediastinal lymphadenopathy. CT guided biopsy of a chest wall mass showed metastatic HCC. A video-assisted thoracoscopy and pleurodesis was performed. The patient opted not to have any further treatment and died in hospice about 2 months after diagnosis of recurrent HCC.

\section{DISCUSSION}

LT is the best treatment for localized HCC in terms of long-term disease free survival. Despite this, patients do have a chance of recurrent HCC that varies from $1.3 \%$ to $44.9 \%$ depending on individual series. ${ }^{[9,13]}$ Multiple studies have determined that microvascular invasion, poor tumor grade, larger tumor diameter, and higher AFP are associated with increased recurrence after transplant. ${ }^{[14-18]}$ Other factors that have been reported to contribute include age, bilobar involvement, multiple lesions, absence of necrosis, tumor beyond Milan criteria, elevated neutrophil-tolymphocyte ratio, microsatellitosis, and previous liver resection. ${ }^{[19-22]}$ Two studies have found that the time between LT and HCC recurrence affects prognosis, with worse outcomes associated with early recurrence within 2 years. ${ }^{[23,24]}$

Once a patient develops a recurrence after transplant, prognostic factors associated with decreased survival include major vascular invasion, poorly-differentiated tumor, unresectable disease, and bone metastases. ${ }^{[4,25]}$ Our small study is consistent with these larger studies in that larger tumors and microvascular invasion on the explanted liver were associated with increased recurrence. Four patients with late recurrence died within 18 months, suggesting that although their initial course after transplantation appeared to be favorable, recurrence at any time threatens survival.

Recurrent HCC tends to occur early or within 2 years of LT. There have been reported cases of recurrent HCC beyond 5 years; however these cases may become more prevalent as more patients are living longer after LT for HCC. Table 5 demonstrates the current literature on recurrence after LT for HCC, which may suggest a trend toward a higher proportion of recurrences with longer follow-up when all cases are considered. ${ }^{[26-30]}$ Castroagudin et al. ${ }^{[31]}$ in 165 cases, reported a $10.9 \%$ recurrence with $78 \%$ of these recurrences occurring within the first 3 years, but they had 3 recipients that had recurrences after 7,9 , and 10 years. In our study, the recurrence rate was $17 \%$ with a third of our recurrence cases occurring beyond 5 years.

In terms of the site of recurrence, most of the cases of recurrent HCC after LT have been reported to involve extrahepatic $(38.5-53 \%)$ or both extrahepatic and intrahepatic sites (31-38.5\%). In general, intrahepatic recurrence is more common in cases of early recurrence, while more extrahepatic involvement is 
seen in cases of late recurrence. ${ }^{[23,32]}$ The lungs are the most common site of extrahepatic involvement, followed by bone involvement. In our late recurrence patients, 4 out of 5 had extrahepatic involvement. Our one case of continued survival after late recurrent HCC (currently over 44 months) had just hepatic involvement. This could potentially be a case of de novo HCC developing in the transplanted liver, the mechanism of which may differ from the biological mechanisms involved in early HCC recurrence.

Treatment of HCC recurrence after transplant involves surgical resection when possible as it has been shown to be associated with a survival advantage. ${ }^{[4,33]}$ Unfortunately, in many cases, patients present with disseminated disease and surgery is not feasible. Other options for treatment include TACE, RFA, high-intensity focused ultrasound ablation, stereotactic body radiation therapy, and modulation of immunosuppressants. ${ }^{[34]}$ Sorafenib, a multikinase inhibitor that improves progression-free and overall survival in patients with advanced HCC, has also shown promising results in treatment of $\mathrm{HCC}$ recurrence post-LT with a modest survival benefit and manageable adverse effects. ${ }^{[35,36]}$ Combination therapy with sorafenib and an mTOR inhibitor such as everolimus has also been used in practice, though longer follow-up studies are needed to assess the benefits versus increased toxicity of such a regimen in recurrent $\mathrm{HCC} .^{[37,38]}$ Our 5 patients with late recurrence were treated with various combinations of resection, RFA, sorafenib, and everolimus. Our single surviving patient had undergone ablation, has been on everolimus/sorafenib, and had resolution of a previously seen intrahepatic lesion.

Once a patient develops recurrence, survival is rather dismal despite efforts to treat these patients. Median survival for patients with recurrence has been reported to be between 8.7 months to 18.3 months from time of recurrence. ${ }^{[4,18,25,33]}$ Our 5 late recurrence cases ranged greatly in survival time after diagnosis of recurrence ( 2 months-over 44 months).

Efforts have been made to better identify molecular factors that predict recurrence after liver resection for HCC. Kim et al. ${ }^{[39]}$ in a cohort of 72 patients in Korea performed gene expression studies on archived tissue samples. They identified a 233 gene signature that was significantly associated with late recurrence after liver resection. From this, they also developed and validated a 4 and 20 gene predictors from the full 233 gene predictors, however this was in a population of primarily hepatitis B HCC. Perhaps similar molecular studies are needed, especially in transplant patients to identify those patients with the potential for late recurrence.

This study is limited by its small sample size and small number of identified cases of late recurrence, which renders it difficult to identify trends and factors that may predispose a patient to develop recurrent HCC. However, our study provides detailed clinical information characterizing five cases of late $\mathrm{HCC}$ recurrence after $L T$, in the hopes that it may benefit other researchers in elucidating the characteristics associated with this fortunately infrequent post-LT complication. A notable observation from this study was that not all of the late recurrences occurred in the liver. This is notable because all the patients underwent LT of primary treatment of HCC. Thus, it can be inferred that the patients experiencing extrahepatic recurrences did so as a consequence of indolent metastases present at the time of transplant. In the 2 cases with intrahepatic recurrence, it is not possible to conclude whether the recurrences were in fact, new tumors arising in the transplanted liver. However, in both cases, patients had difficult to control-viral hepatitis and it is possible that hepatitis and fibrosis predisposed them to recurrent HCC in the liver. Because nearly one-third of our post-LT patients with recurrent HCC experienced recurrence more than 5 years after LT, our study highlights the importance of long-term follow-up with imaging every 6-12 months and the need for biomarkers to identify patients who may be at risk for late recurrences. We encourage future studies to further characterize patients with late recurrence of HCC and perhaps molecular studies could help better identify those patients at greatest risk for recurrence to allow physicians to monitor these patients more vigilantly.

\section{Authors' contributions}

Study design: S.A. Kwee, L.L .Wong

Data analysis: J.A. Zhang

Manuscript preparation: J.A. Zhang, L.L.Wong

Critical review of manuscript: S.A. Kwee

\section{Financial support and sponsorship}

This study was supported by $\mathrm{NIH}$ grant 2 P30 CA071789-13.

\section{Conflicts of interest}

Dr. Wong is on the speaker bureau for Bayer Healthcare. Dr. Kwee and Ms. Zhang have no conflicts of interest to report.

\section{Patient consent}

This is a retrospective study and the Institutional 
Review Board did not require patient consent for this study.

\section{Ethics approval}

This study was approved by the Institutional Review Board at the University of Hawaii.

\section{REFERENCES}

1. Ferlay J, Soerjomataram I, Dikshit R, Eser S, Mathers C, Rebelo M, Parkin DM, Forman D, Bray F. Cancer incidence and mortality worldwide: sources, methods and major patterns in GLOBOCAN 2012. Int J Cancer 2015;136:E359-86.

2. Chiao H, Yang CE, Frenette CT. Review on liver transplant for hepatocellular carcinoma. Transl Center Res 2013;2:472-81.

3. Rubin J, Ayoub N, Kaldas F, Saab S. Management of recurrent hepatocellular carcinoma in liver transplant recipients: a systematic review. Exp Clin Transplant 2012;10:531-43.

4. Roayaie S, Schwartz JD, Sung MW, Emre SH, Miller CM, Gondolesi GE, Krieger NR, Schwarz ME. Recurrence of hepatocellular carcinoma after liver transplant: patterns and prognosis. Liver Transpl 2004; 10:534-40.

5. State Cancer Profiles. Available from: www.statecancerprofiles. cancer/gov. [Last accessed on December 24, 2016].

6. US Census data: Quick Facts-Hawaii. Avaiblale from: www.census. gov. [Last accessed on December 24, 2016].

7. Wong LL, Hernandez B, Kwee S, Albright CL, Okimoto G, Tsai N. Healthcare disparities in Asians and Pacific Islanders with hepatocellular cancer. Am J Surg 2012;203:726-32.

8. Bruix J, Sherman M, American Association for the Study of the Liver Disease. Management of hepatocellular carcinoma: an update. Hepatology 2011;53:1020-2.

9. Hwang S, Ahn CS, Kim KH, Moon DB, Ha TY, Song GW, Jung DH, Park GC, Yu YD, Park PJ, Choi YI, Kim KW, Lim YS, Lee HC, Yu ES, Lee SG. Super-selection of a subgroup of hepatocellular carcinoma patients at minimal risk of recurrence for LT. $J$ Gastrointest Surg 2011;15:971-81.

10. Lee S, Hyuck David Kwon C, Man Kim J, Joh JW, Woon Paik S, Kim BW, Wang HJ, Lee KW, Suh KS, Lee SK. Time of hepatocellular carcinoma recurrence after liver resection and alphafetoprotein are important prognostic factors for salvage liver transplantation. Liver Transpl 2014;20:1057-63.

11. Schraiber Ldos S, de Mattos AA, Zanotelli ML, Cantisani GP, Brandão AB, Marroni CA, Kiss G, Ernani L, Marcon Pdos S. Alpha-fetoprotein level predicts recurrence after transplantation in hepatocellular carcinoma. Medicine (Baltimore) 2016;95:e2478.

12. Hanouneh IA, Macaron C, Lopez R, Aucejo F, Zein NN. Rate of tumor growth predicts recurrence of hepatocellular carcinoma after LT in patients beyond Milan or UCSF criteria. Transplant Proc 2011;43:3813-8.

13. Andreou A, Bahra M, Schmelzle M, Öllinger R, Sucher R, Sauer IM, Guel-Klein S, Struecker B, Eurich D, Klein F, Pascher A, Pratschke J, Seehofer D. Predictive factors for extrahepatic recurrence of hepatocellular carcinoma following liver transplantation. Clin Transplant 2016;30:819-27.

14. Kondili LA, Lala A, Gunson B, Hubscher S, Olliff S, Elias E, Bramhall S, Mutimer D. Primary hepatocellular cancer in the explanted liver: outcome of transplantation and risk factors for HCC recurrence. Eur J Surg Oncol 2007;33:868-73.

15. Escartin A, Sapisochin G, Bilbao I, Vilallonga R, Bueno J, Castells L, Dopazo C, Castro E, Caralt M, Balsells J. Recurrence of hepatocellular carcinoma after liver transplantation. Transplant Proc
2007;39:2308-10.

16. Varona MA, Soriano A, Aguirre-Jaime A, Garrido S, Oton E, Diaz D, Portero J, Bravo P, Barrera MA, Perera A. Risk factors of hepatocellular carcinoma recurrence after liver transplantation: accuracy of the alpha-fetoprotein model in a single-center experience. Transplant Proc 2015;47:84-9.

17. Lai Q, Avolio AW, Lerut J, Singh G, Chan SC, Berloco PB, Tisone G, Agnes S, Chok KS, Sharr W, Rossi M, Manzia TM, Lo CM. Recurrence of hepatocellular cancer after liver transplantation: the role of primary resection and salvage transplantation in East and West. J Hepatol 2012;57:974-9.

18. Chan KM, Chou HS, Wu TJ, Lee CF, Yu MC, Lee WC. Characterization of hepatocellular carcinoma recurrence after liver transplantation: perioperative prognostic factors, patterns, and outcome. Asian J Surg 2011;34:128-34.

19. Lai Q, Avolio Aw, Graziadei I, Otto G, Rossi M, Tisone G, Goffette P, Vogel W, Pitton MB, Lerut J; European Hepatocellular Cancer Liver Transplant Study Group. Alpha-fetoprotein and modified response evaluation criteria in solid tumors progression after locoregional therapy as predictors of hepatocellular cancer recurrence and death after transplantation. Liver Transpl 2013;19:1108-18.

20. Agopian VG, Harlander-Locke M, Zarrinpar A, Kaldas FM, Farmer DG, Yersiz H, Finn RS, Tong M, Hiatt JR, Busuttil RW. A novel prognostic nomogram accurately predicts hepatocellular carcinoma recurrence after liver transplantation: analysis of 865 consecutive liver transplant recipients. $J$ Am Coll Surg 2015;220:416-27.

21. Parfitt JR, Marotta P, Alghamdi M, Wall W, Khakhar A, Suskin NG Quan D, McAllister V, Ghent C, Levstik M, McLean C, Chakrabarti S, Garcia B, Driman DK. Recurrent hepatocellular carcinoma after transplantation: use of a pathological score on explanted livers to predict recurrence. Liver Transpl 2007;13:543-51.

22. Oligane HC, Xing M, Kim HS. Effect of bridging local-regional therapy on recurrence of hepatocellular carcinoma and survival after orthotopic liver transplantation. Radiology 2017;282:869-79.

23. Chok KS, Chan SC, Cheung TT, Chan AC, Fan ST, Lo CM. Late recurrence of hepatocellular carcinoma after liver transplantation. World J Surg 2011;35:2058-62.

24. Toso C, Cader S, Mentha-Dugerdil A, Meeberg G, Majno P, Morard I, Giostra E, Berney T, Morel P, Mentha G, Kneteman NM. Factors predicting survival after post-transplant hepatocellular carcinoma recurrence. J Hepatobiliary Pancreat Sci 2013;20:342-7.

25. Shin WY, Suh KS, Lee HW, Kim J, Kim T, Yi NJ, Lee KU Prognostic factors affecting survival after recurrence in adult living donor transplantation for hepatocellular carcinoma. Liver Transpl 2010;16:678-84

26. Zou WL, Zang YJ, Chen XG, Shen ZY. Risk factors for fatal recurrence of hepatocellular carcinoma and their role in selecting candidates for liver transplantation. Hepatobiliary Pancreat Dis Int 2008;7:145-51.

27. Rodriguez-Peralvarez M, Tsochatzis E, Naveas MC, Pieri G, GarciaCaparros C, O’Beirne J, Poyato-Gonzalez A, Ferrin-Sanchez G, Montero-Alvarez JL, Patch D, Thorburn D, Briceno J, De la Mata M, Burroughs AK. Reduced exposure to calcineurin inhibitors early after liver transplantation prevents recurrence of hepatocellular carcinoma. J Hepatol 2013;59:1193-9.

28. Nissen NN, Menon V, Bresee C, Tran TT, Annamalai A, Poordad F, Fair JH, Klein AS, Boland B, Colquhoun SD. Recurrent hepatocellular carcinoma after liver transplant: identifying the highrisk patient. HPB (Oxford) 2011;13:626-32.

29. Pfiffer TB, Seehofer D, Nicolaou A, Neuhaus R, Riess H, Trappe RU. Recurrent hepatocellular carcinoma in liver transplant recipients: parameters affecting time to recurrence, treatment options and survival in the sorafenib era. Tumori 2011;97:436-41.

30. Marelli L, Grasso A, Pleguezuelo M, Martines H, Stigliano R, 
Dhillon AP, Patch D, Davidson BR, Sharma D, Rolles K, Burroughs AK. Tumour size and differentiation in predicting recurrence of hepatocellular carcinoma after liver transplantation: external validation of a new prognostic score. Ann Surg Oncol 2008;15:3503-11.

31. Castroagudin JF, Molina-Pérez E, Ferreiro-Iglesias R, Abdulkader I, Otero-Antón E, Tomé S, Varo-Pérez E. Late recurrence of hepatocellular carcinoma after liver transplantation: is an active surveillance for recurrence needed? Transplant Proc 2012;44:1565-7.

32. Schreibman IR, Bejarano P, Martinez EJ, Regev A. Very late recurrence of hepatocellular carcinoma after LT: case report and literature review. Transplant Proc 2006;38:3140-43.

33. Bodzin AS, Lunsford KE, Markovic D, Harlander-Locke MP, Busuttil RW, Agopian VG. Predicting mortality in patients developing recurrent hepatocellular carcinoma after liver transplantation: impact of treatment modality and recurrence characteristics. Ann Surg 2016; DOI:10.1097/SLA.0000000000001894.

34. Chok KSH. Management of recurrent hepatocellular carcinoma after liver transplant. World J Hepatol 2015;7:1142-8.

35. Lee HY, Yang KH, Choi BH, Park YM, Yoon KT, Ryu JH, Chu CW. Complete regression of recurrent advanced hepatocellular carcinoma after liver transplantation in response to sorafenib treatment: a case report. Transplant Proc 2016;48:247-50.

36. Sposito C, Mariani L, Germini A, Flores Reyes M, Bongini M, Grossi G, Bhoori S, Mazzaferro V. Comparative efficacy of sorafenib versus best supportive care in recurrent hepatocellular carcinoma after liver transplantation: a case-control study. J Hepatol 2013;59:59-66.

37. De Simone P, Crocetti L, Pezzati D, Bargellini I, Ghinolfi D, Carrai P, Leonardi G, Della Pina C, Cioni D, Pollina L, Campani
D, Bartolozzi C, Lencioni R, Filipponi F. Efficacy and safety of combination therapy with everolimus and sorafenib for recurrence of hepatocellular carcinoma after liver transplantation. Transplant Proc 2014;46:241-4.

38. Gomez-Martin C, Bustamante J, Castroagudin JF, Salcedo M, Garralda E, Testaillano M, Herrero I, Matilla A, Sangro B. Efficacy and safety of sorafenib in combination with mammalian target of rapamycin inhibitors for recurrent hepatocellular carcinoma after liver transplantation. Liver Transpl 2012;18:45-52.

39. Kim JH, Sohn BH, Lee HS, Kim SB, Yoo JE, Park YY, Jeong W Lee SS, Park ES, Kaseb A, Kim BH, Kim WB, Yeon JE, Byun KS, Chu IS, Kim SS, Wang XW, Thorgeirsson SS, Luk JM, Kang KJ, Heo J, Park YN, Lee JS. Genomic predictors for recurrence patterns of hepatocellular carcinoma: model derivation and validation. PLoS Med 2014;11:e1001770.

40. Sharma P, Welch K, Hussain H, Pelletier SJ, Fontana RJ, Marrero J Merion RM. Incidence and risk factors of hepatocellular carcinoma recurrence after liver transplantation in the MELD era. Dig Dis Sci 2012;57:806-12.

41. Wai CT, Woon WA, Tan YM, Lee KH, Tan KC. Younger age and presence of macrovascular invasion were independent significant factors associated with poor disease-free survival in hepatocellular carcinoma patients undergoing living donor liver transplantation. Transplant Proc 2012;44:516-9.

42. Iacob R, Iacob S, Gheorghe L, Gheorghe C, Hrehoret D, Brasoveanu V, Croitoru A, Herlea V, Popesu I. Outcome of liver transplantation for hepatocellular carcinoma -- a single center experience. Chirurgia (Bucur) 2013;108:446-50 